\title{
Scaled biotic disruption during early Eocene global warming events
}

\author{
S. J. Gibbs ${ }^{1}$, P. R. Bown ${ }^{2}$, B. H. Murphy ${ }^{3}$, A. Sluijs ${ }^{4}$, K. M. Edgar ${ }^{1, *}$, H. Pälike ${ }^{1}$, C. T. Bolton ${ }^{5}$, and J. C. Zachos ${ }^{3}$ \\ ${ }^{1}$ Ocean and Earth Sciences, National Oceanography Centre Southampton, University of Southampton, European Way, \\ Southampton, SO14 3ZH, UK \\ ${ }^{2}$ Department of Earth Sciences, University College London, Gower Street, London WC1E 6BT, UK \\ ${ }^{3}$ Department of Earth and Planetary Sciences, University of California, Santa Cruz, CA 95064, USA \\ ${ }^{4}$ Biomarine Sciences, Institute of Environmental Biology, Utrecht University, Laboratory of Palaeobotany and Palynology, \\ Budapestlaan 4, 3584CD, Utrecht, The Netherlands \\ ${ }^{5}$ Departamento de Geologia, Universidad de Oviedo, Arias de Velasco, 33005 Oviedo, Asturias, Spain \\ *now at: School of Earth and Ocean Sciences, Cardiff University, Main Building, Park Place, CF10 3AT, Cardiff, UK
}

Correspondence to: S. J. Gibbs (sxg@noc.soton.ac.uk)

Received: 9 January 2012 - Published in Biogeosciences Discuss.: 30 January 2012

Revised: 31 October 2012 - Accepted: 1 November 2012 - Published: 22 November 2012

\begin{abstract}
Late Paleocene and early Eocene hyperthermals are transient warming events associated with massive perturbations of the global carbon cycle, and are considered partial analogues for current anthropogenic climate change. Because the magnitude of carbon release varied between the events, they are natural experiments ideal for exploring the relationship between carbon cycle perturbations, climate change and biotic response. Here we quantify marine biotic variability through three million years of the early Eocene that include five hyperthermals, utilizing a method that allows us to integrate the records of different plankton groups through scenarios ranging from background to major extinction events. Our long time-series calcareous nannoplankton record indicates a scaling of biotic disruption to climate change associated with the amount of carbon released during the various hyperthermals. Critically, only the three largest hyperthermals, the Paleocene-Eocene Thermal Maximum (PETM), Eocene Thermal Maximum 2 (ETM2) and the I1 event, show above-background variance, suggesting that the magnitude of carbon input and associated climate change needs to surpass a threshold value to cause significant biotic disruption.
\end{abstract}

\section{Introduction}

Late Paleocene through early Eocene hyperthermals occurred against a backdrop of long-term climate warming between $\sim 60$ and $\sim 50$ million years ago (Ma) (e.g. Cramer et al., 2003; Lourens et al., 2005; Quillévéré et al., 2008; Zachos et al., 2010). All are characterized by negative carbon isotope excursions (CIEs) and deep-sea carbonate dissolution (Lourens et al., 2005; Zachos et al., 2005), indicating the release and/or redistribution of massive amounts of ${ }^{13} \mathrm{C}$ depleted carbon between carbon reservoirs (e.g. Cramer et al., 2003; Lourens et al., 2005; Sexton et al., 2011; Lunt et al., 2011). The PETM ( $56 \mathrm{Ma})$ was the largest and most abrupt of these hyperthermals with a marine CIE of 2.5$4.0 \%$, accompanying lysocline shoaling of more than two kilometers and global warming of 5 to $8^{\circ} \mathrm{C}$ (Sluijs et al., 2007a; Zachos et al., 2005). This climate event was accompanied by dramatic biotic changes, including migration of terrestrial mammals, extinction of benthic foraminifera and a global expansion of tropical plankton (e.g. Sluijs et al., 2007a; McInerney and Wing, 2011). ETM2 or H1 ( 54 Ma) was the second largest hyperthermal with a CIE of $\sim 1.5 \%$ o and $\sim 3^{\circ} \mathrm{C}$ warming (Lourens et al., 2005; Sluijs et al., 2009; Stap et al., 2010). Approximately 100 kiloyears (kyr) later, the $\mathrm{H} 2$ event occurred with a CIE of $\sim 0.8 \%$ and warming of $\sim 2{ }^{\circ} \mathrm{C}$ (Stap et al., 2010). The relationships between magnitude of CIE and degree of inferred warming are comparable, at least regionally, for the PETM, ETM2 and H2 events, 


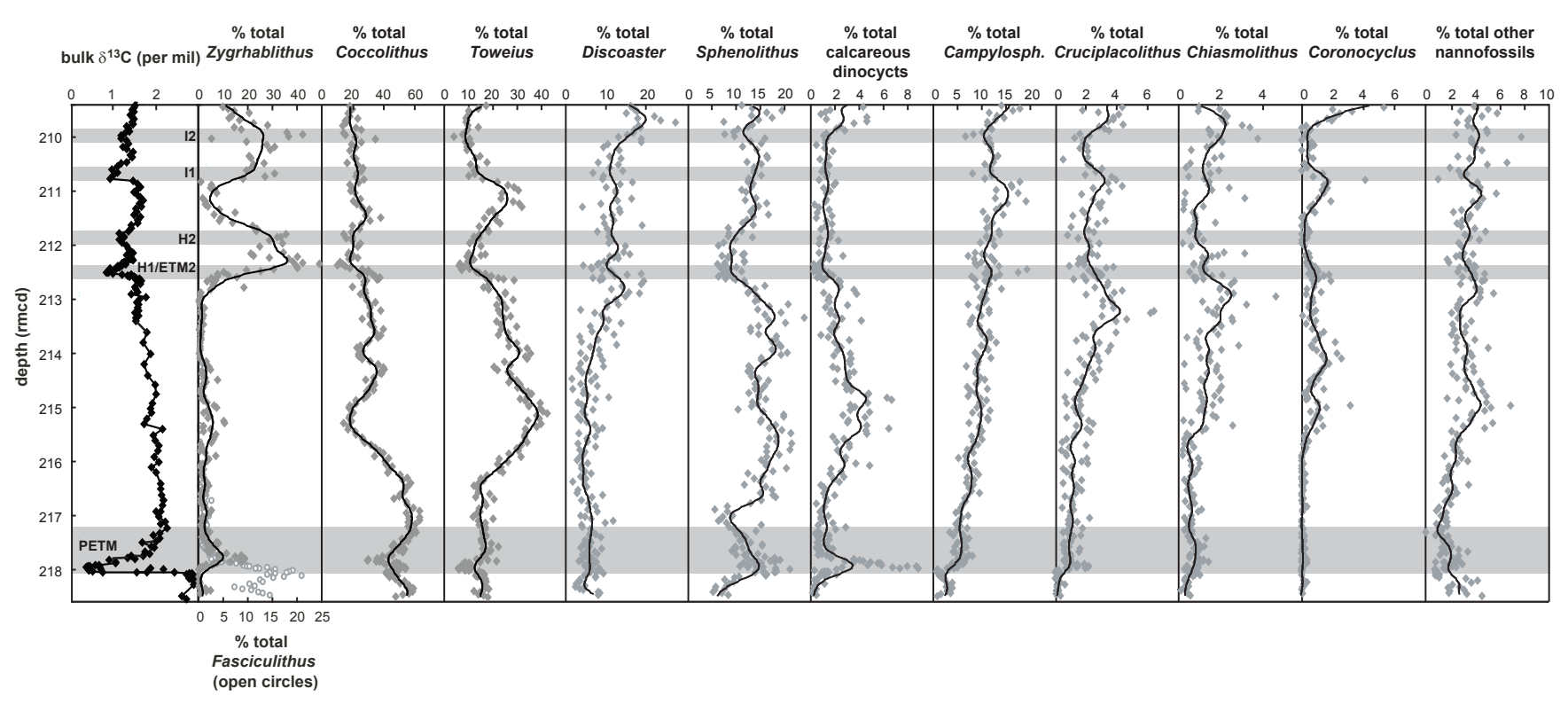

Fig. 1. Abundances of the most common taxa across the focal interval, illustrating raw percent data (grey diamonds) and the SiZer smoothed records (black lines), on a depth scale. In the first panel is the bulk carbonate carbon isotope record (Zachos et al., 2003; Murphy et al., 2006) with the CIE intervals highlighted in grey. Campylosp. - Campylosphaera. Depth - revised metres composite depth (rmcd, Westerhold and Röhl, 2006).

suggesting that the isotopic composition and release mechanism of the injected carbon were similar across these events (Stap et al., 2010; Abels et al., 2012). These closely spaced CIEs/climate change events of different magnitudes provide enormous potential for quantifying biological sensitivity to carbon cycle perturbations. However, as new biotic records of these hyperthermals emerge, we require techniques that enable the consistent and quantitative assessment of magnitude and significance of biotic change in multi-taxic datasets. Here, we apply a modified coefficients of variation technique to quantify levels of variation in a long time-series record of calcareous nannoplankton abundance across multiple hyperthermals, and compare these results with data from other plankton groups and from the mass extinction event at the Cretaceous-Paleogene boundary.

\section{Material and nannofossil data}

We generated high-resolution calcareous nannoplankton (nannofossil) assemblage records across a nine-meter section at Ocean Drilling Program (ODP) Site 1209 (32 $39.11 \mathrm{~N}$, $158^{\circ} 30.36 \mathrm{E}$, present-day water depth $2387 \mathrm{~m}$ ) in the paleosubequatorial Pacific Ocean (Fig. 1). This section spans five CIEs, the PETM, ETM2, H2, I1 and I2, from $\sim 53.0$ to $\sim 56.2$ $\mathrm{Ma}$ (nomenclature following Cramer et al., 2003; Zachos et al., 2010). The CIEs are recorded in the isotopic composition of bulk sediment carbonate (Murphy et al., 2006) and typically correspond to clay-rich dissolution horizons, illustrated by the magnetic susceptibility record (Fig. 2b). Although some dissolution is evident during this interval at Site 1209, it is less severe than, for example, the deeper sites in the Walvis Ridge PETM transect (2717-4755 m water-depth; Zachos et al., 2005). The age model for Site 1209 uses tie-points in the $\delta^{13} \mathrm{C}$ record to correlate with the orbitally tuned stratigraphy and absolute ages of ODP Site 1262, summarized in Zachos et al. (2010) (Fig. 2a).

Assemblage data (\% abundances) are based on statistically significant abundance counts of $\sim 600-800$ nannofossils per sample (Gibbs et al., 2006b), and were collected at $4-5 \mathrm{~cm}$ $(\sim 13 \mathrm{kyr})$ spacing. Species-level counts were performed on the samples taken across the ETM2, to complement existing data from the PETM (Gibbs et al., 2006b). Species were grouped into genera and ranked according to average abundances, with $>97 \%$ of the assemblage typically represented by around 10 genera. For the long time-series samples, we counted generic groups, selecting the genera that include the ten most abundant across the PETM and the ETM2, together 11 genera (see discussion in Sect. 3.1 below) (Fig. 1).

\section{Methods, analytical approach and sensitivity tests}

Our approach to quantifying and comparing biotic variability across the hyperthermal events required (1) a means of utilizing routinely collected relative abundance data, (2) a technique ideally independent of taxic composition (which may vary with time and space due to evolution and biogeography, as well as between specialists), (3) a means to objectively quantify overall assemblage variability but remove 


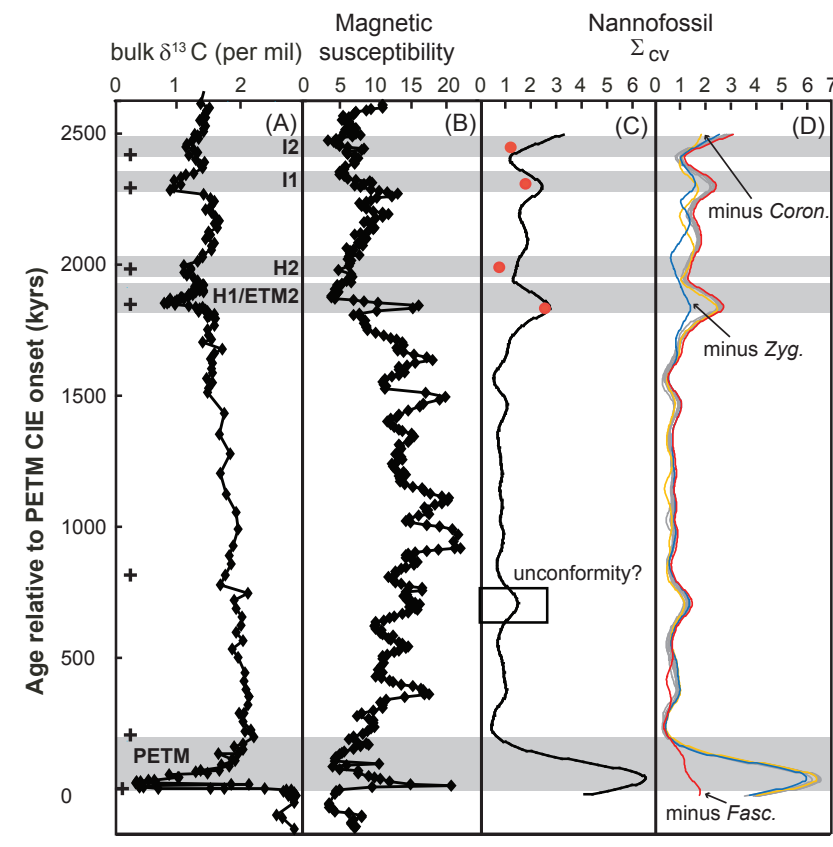

Fig. 2. Carbon isotope, magnetic susceptibility and calcareous nannofossil records from the Paleocene-Eocene interval at ODP Site 1209 plotted against age relative to the PETM onset. Panel (A) is the bulk carbonate carbon isotope record (Zachos et al., 2003; Murphy et al., 2006), with the CIEs highlighted in grey, and chronostratigraphic tie-points indicated by black crosses. Panel (B) shows magnetic susceptibility (Bralower et al., 2002). Panel (C) shows summed coefficients of variation $\left(\Sigma_{\mathrm{cv}}\right)$ across age windows of $150 \mathrm{kyr}$ (in black), with values calculated across the duration of each CIE shorter than $150 \mathrm{kyr}$, indicated by red circles. Panel (D) is the $\Sigma_{\mathrm{cv}}$ record excluding individual taxa: only the records excluding Coronocyclus (yellow), Zygrhablithus (blue) and Fasciculithus (red) are indicated in colour; the rest of the records are virtually indistinguishable from one another and are shaded in grey.

dominance-biasing by a small number of taxa, and, (4) the application of an objective means to maximize signal-tonoise. These requirements are met by combining a method of generating the best-smoothed fit (significant zero crossings of derivatives, SiZer; Chaudhuri and Marron, 1999), followed by a quantitative assessment of assemblage variability (summed coefficients of variation, $\Sigma_{\mathrm{cv}}$ ).

\subsection{Relative abundance and genus level data}

For the deep-time geological records studied here, we consider that relative abundance data are the most appropriate as a first-order approximation of relative biological change using the least degraded data, and an objective measure of variance that allows comparison between different stratigraphic levels, different sites and different fossil groups. Relative abundance data are a robust record of population/assemblage dynamics and thus a measure of primary biological interac- tion and response. It is a commonly applied and relatively rapidly produced data type, which facilitates the comparison of published datasets from different locations and time intervals. Although cognisant of closed sum problems, we have tested for these effects by using a ranking analysis, described below. We did not attempt to generate "absolute" numbers per gram or flux-estimates-type data, because such methods require continuous high-resolution age models, are highly sensitive to sedimentation rate changes, and preparation methodology varies widely. This renders the comparison of data problematic, and each methodological step potentially introduces error and degrades the data.

We also chose to adopt a genus-level counting approach to facilitate rapid data capture. Nannofossil genera represent robust groupings of taxa with very similar morphology, and generic classification in nannofossils is typically more stable and less ambiguous than species level, which is particularly important for long time-series studies. Furthermore, morphospecies within genera typically share similar ecologies; e.g. Discoaster are thermophylic and Toweius are cosmopolitan bloom-formers. While it might be argued that combining species reduces the variance signal, there are two points to consider here. First, combining species does not inherently result in loss of variance signal, as integrated records will comprise variance from multiple species that is not automatically lost or cancelled out. Loss may occur if all the species co-varied (but even this could still produce a relatively high level of variance), or if abundance changes occurred at a frequency that cancelled each other out. Second, this is a relatively moot point in our dataset where, of the 11 genera that comprise the Eocene hyperthermals dataset, seven effectively record only one species. Coccolithus and Zygrhablithus are essentially monospecific here, and Campylosphaera, Cruciplacolithus, Chiasmolithus, Coronocyclus and Sphenolithus are represented by few species and dominated by one. The remaining taxa, Fasciculithus, Toweius and Discoaster, are multi-species signals, but species within these groups share similar ecologies. Moreover, the taxonomy of morphospecies within Fasciculithus and Discoaster is particularly inconsistent between authors due to very plastic and intergrading morphotypes; thus genus-level data provide a more robust method of capturing comparable data in these groups. Therefore, the genera we count, regardless of whether they are monospecific or multi-species groups, are valid morphogroups, which are internally consistent through time and provide reliable and comparable taxonomic data.

\subsection{Combined smoothing and variance techniques}

The relative abundance record of each taxon was individually run through the SiZer program to produce a smoothed record that shows the least degradation but highest confidence in signal (Fig. 1). The SiZer technique generates a set of smoothed curves, which use the full range of bandwidths available, and provides criteria by which the most 


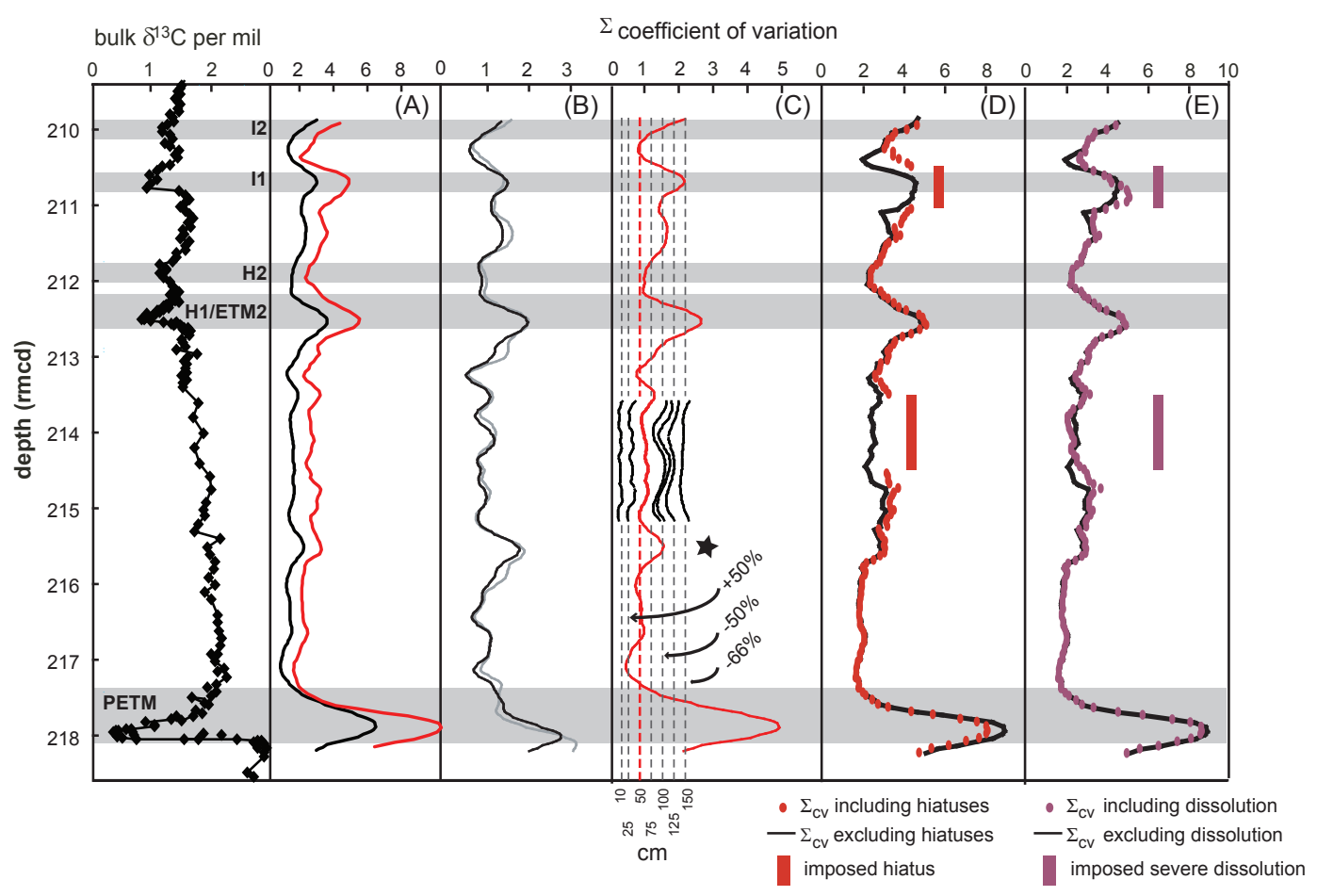

Fig. 3. Sensitivity tests and comparison of downcore summed coefficients of variation (CV) records calculated using smoothed and original raw percent abundance data. Panel (A) shows $\Sigma_{\mathrm{cv}}$ records from smoothed and raw data. Panel (B) is a comparison of total summed CVs of the smoothed data using CVs divided by the taxon's average across $50 \mathrm{~cm}$ (grey line) and $100 \mathrm{~cm}$ windows (black line), whereas in Panel (A) the CVs are divided by the taxon's average abundance across the entire interval. Panel (C) is a comparison of background $\Sigma_{\mathrm{Cv}}$ values that result from different window sizes, extrapolated as vertical dashed lines; the $50 \mathrm{~cm}$ background $\Sigma_{\mathrm{cv}}$ level is highlighted in red. Also marked is the sedimentation rate change equivalent (in percent) to which these background levels correspond. Panels (D) and (E) show the results of artificially introduced hiatuses and intervals of intense dissolution, respectively. The star indicates the levels of a possible natural hiatus. The original $\Sigma_{\mathrm{cv}}$ record is shown in black and the records that include imposed hiatuses and dissolution are shown in red and purple, respectively. Red and purple vertical bars highlight the intervals where hiatuses and dissolution have been introduced.

appropriate of these smoothed curves can be chosen (Chaudhuri and Marron, 1999; Chaudhuri et al., 2012; Wagner, 2012; see the application to palaeoceanographic records in Rohling and Pälike, 2005). Smoothing removes part of the noise inherent to these types of data, but using SiZer we introduce a transferable, objective set of criteria by which to increase the signal-to-noise ratio. We have tested for any signal loss by analysing smoothed and non-smoothed records, and similar trends are seen in both results (Fig. 3a). However, the records of summed coefficients of variation $\left(\Sigma_{\mathrm{cv}}\right)$ from the SiZer smoothed abundances are consistently around half the amplitude of the $\Sigma_{\mathrm{cv}}$ values from the raw relative abundances. As no signal loss results from the SiZer smoothing, we have applied smoothing in order to facilitate comparisons between datasets that may contain different levels of noise.

Following SiZer smoothing, we calculated and summed the $\Sigma_{\mathrm{cv}}$ for the most abundant taxa across moving windows. We used windows of $150 \mathrm{kyr}$, to capture the majority of each CIE (Figs. 2c and 4a), and windows of $25 \mathrm{kyr}$ to resolve patterns within each CIE. This latter window duration is the shortest achievable with the sampling resolution of the data
(Fig. 4b). Because we want to directly compare net assemblage change across each event, we also calculated coefficients of variation (CV) across only the duration of each of the CIEs that are shorter than 150 kyr (Figs. 2c and 4a).

$\mathrm{CVs}$ are calculated by determining the standard deviation of taxon abundance over a given stratigraphic interval, divided by the taxon's mean abundance (Eq. 1, Fig. 3a and b). This provides a normalised measure of the spread of data about the arithmetic mean. Dividing the standard deviation by the average abundance is necessary in order to remove bias towards high abundance taxa. More abundant taxa can have a disproportionately large standard deviation, but equally, rare taxa that, for example, fluctuate between absence and rare occurrence would have a large standard deviation when divided by their average low abundance. Therefore we have excluded the CVs of rare taxa $(<0.7 \%)$ from the Site 1209 record, leaving 11 taxa which contribute $>97 \%$ of the assemblage. We have then summed the CVs for the most common taxa to gain a quantified estimate of overall assemblage variance (Eq. 1). 


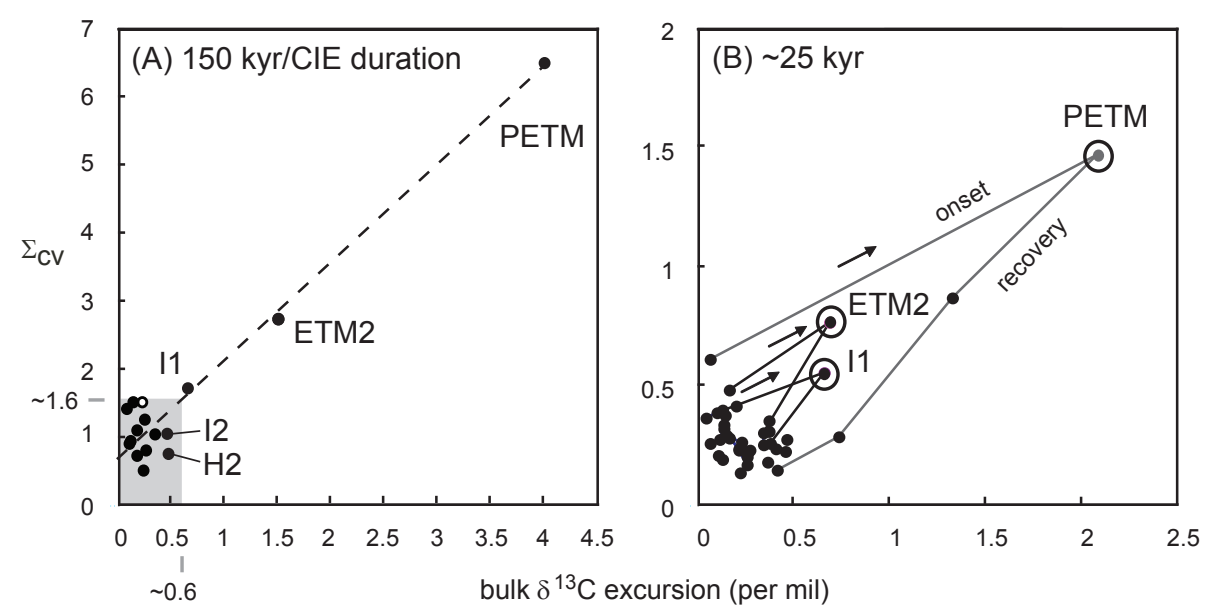

Fig. 4. Scatter plots of summed coefficients of variation $\left(\Sigma_{\mathrm{cv}}\right)$ against magnitude of carbon isotope excursion. Panel (A) shows the $\Sigma_{\mathrm{cv}}$ values from Fig. 2c plotted for each peak (using the values highlighted by red circles for H2, I1 and I2) and every intervening $150 \mathrm{kyr}$. The positions of the $\Sigma_{\mathrm{cv}}$ data points for the PETM and ETM2 are shown against inferred maximum bulk carbonate $\delta^{13} \mathrm{C}$ values (Lourens et al., 2005; Zachos et al., 2005). The level of a suspected unconformity, at $\sim 700 \mathrm{kyr}$ above the PETM onset, is plotted as an open black circle and the grey area represents a "background" field. Panel (B) shows the $\Sigma_{\mathrm{cv}}$ values across $25 \mathrm{kyr}$ with values plotted for the peak excursions (open black circles) and every intervening $50 \mathrm{kyr}$. Only data that are spaced at least as widely apart as the CV window are plotted in order for each data point to be independent of its neighbours. Stratigraphically adjacent data points are joined by lines with the arrows indicating the up-section direction.

$\sum_{n=1: 11}\left(\frac{S D_{n, t_{1} \rightarrow t_{2}}}{\operatorname{mean}_{n, t_{1} \rightarrow t_{2}}}\right)$

where $t_{1}$ and $t_{2}$ are the start and end of the window, $n$ being the number of taxa.

In order to explore the influence of each taxon on the downcore record of $\Sigma_{\mathrm{cv}}$, we recalculated the $\Sigma_{\mathrm{cv}}$ values multiple times, each time removing a different taxon (Fig. 2d). We can see that three key taxa dominate in different portions of the record: Coronocyclus, Zygrhablithus and Fasciculithus. For example, Fasciculithus dominates the PETM $\Sigma_{\mathrm{cv}}$ values, which is not unexpected given that the abundance and diversity loss of this genus is one of the characteristic features of the event. Therefore, the combination of taxa ensures that we have an integrated picture of assemblage change where variance occurs in different taxa at different stratigraphic levels.

We have also applied the $\Sigma_{\mathrm{cv}}$ technique to other published PETM datasets, including planktic foraminiferal and dinoflagellate cyst records (see Fig. 5a caption), choosing records with the necessary temporal resolution, at least $\sim 20 \mathrm{kyr}$ sampling interval, to allow for a reasonable comparison of data. We used a window size corresponding to the total duration of the PETM, and have plotted peak and background values in Fig. 5a. Note that, for the Bass River datasets, the resultant $\Sigma_{\mathrm{cv}}$ values may be underestimates as the full duration of the CIE is not recorded. In addition, we also applied the method in two sections that include the Cretaceous-Paleogene boundary (K-Pg, $\sim 65 \mathrm{Ma}$ ), from
ODP Sites 1210 and 1262 (Bown, 2005; Bernaola and Monechi, 2007), to provide comparison with the nearest mass extinction event (Fig. 5b). To facilitate direct quantitative comparison, we used the 11 most abundant nannofossil taxa, including both outgoing Cretaceous and incoming Paleocene taxa, but excluded any obvious reworking of Cretaceous taxa in Paleocene sediments.

\subsection{Sensitivity tests and controls on the summed coeffi- cients of variation record}

The magnitude of CVs will be a function of sample window duration, which, ideally, is kept constant. However, sedimentological factors that influence temporal resolution, such as sedimentation rate and hiatuses, may modify the effective window duration. In the Site 1209 analysis, for example, there may be some variation in window duration due to changes in sedimentation rate, occurring at a resolution higher than the applied age model. These biases may impact $\Sigma_{\mathrm{cv}}$ values and need to be considered when interpreting the records. We have therefore tested the sensitivity of $\Sigma_{\mathrm{cv}}$ values by exploring the impact of varying window size and by artificially introducing hiatuses and dissolution. These tests have been applied to the depth record so we can assess how changes in sedimentation rate may influence the signal in the age-domain data. First, we calculated $\Sigma_{\mathrm{cv}}$ using different window durations from $10 \mathrm{~cm}$ up to $150 \mathrm{~cm}$ (Fig. 3c). As expected, $\Sigma_{\mathrm{cv}}$ values are higher when a greater depth window is applied because greater stratigraphic duration is being incorporated into each window, equivalent to 


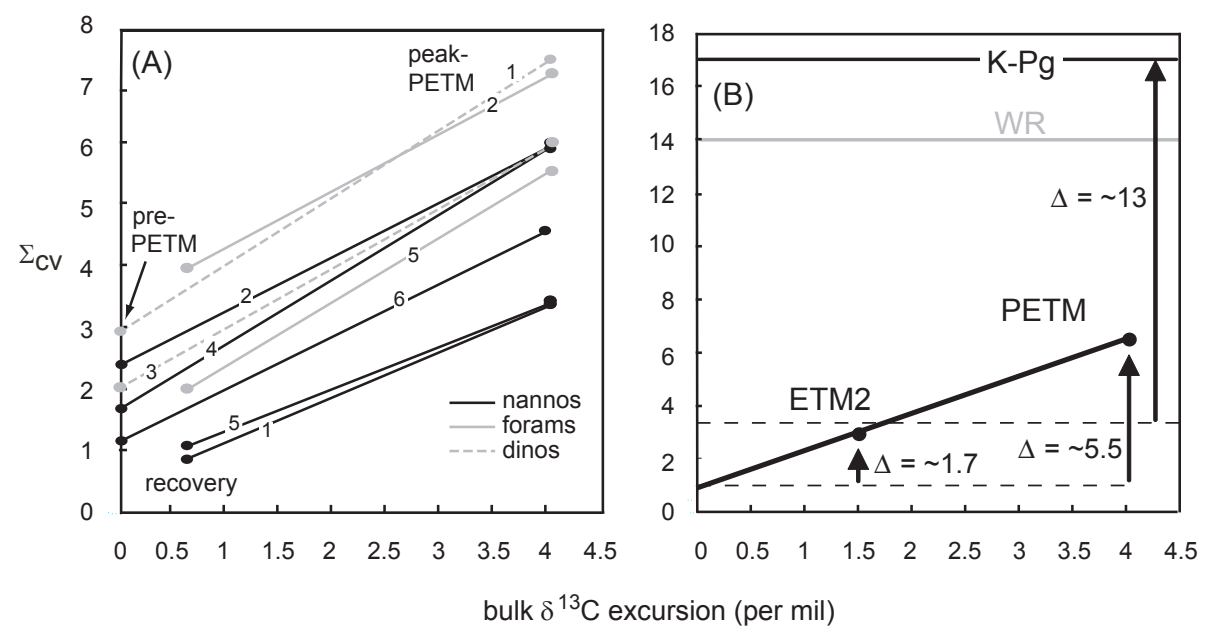

Fig. 5. Scatter plots of summed coefficients of variation $\left(\Sigma_{\mathrm{cv}}\right)$ against magnitude of CIE for different plankton groups and for comparison with the Cretaceous-Paleogene boundary mass extinction event. Panel (A) shows background and peak PETM $\Sigma_{\mathrm{cv}}$ values for multiple PETM sites - nannofossils (black circles, black lines), planktic foraminifera (grey circles, grey lines) and dinoflagellate cysts (grey circles, grey dashed lines). Where possible pre-event $\Sigma_{\mathrm{cv}}$ values are plotted but where missing, then the $\Sigma_{\mathrm{cv}}$ values from the recovery interval are used. 1 - ODP onshore drill site Bass River (nannofossils (Gibbs et al., 2010) and dinocysts (Sluijs and Brinkhuis, 2009)); 2 - ODP Site 690, Southern Ocean (nannofossils (Bralower, 2002) and planktic foraminifera (Kelly, 2002)); 3 - Lomonosov Ridge, Arctic Ocean (dinocysts (Sluijs et al., 2008)); 4 - TDP, Tanzanian drilling project Site 14 (nannofossils (Bown and Pearson, 2009)); 5 - ODP Site 1209 (nannofossils - herein - and planktic foraminifera (Petrizzo, 2007)); 6 - ODP Site 1260, Demerara Rise, Atlantic Ocean (nannofossils (Mutterlose et al., 2007)). All $\Sigma_{\mathrm{cv}}$ data use 10 taxa for comparison or, for the foraminifera data, normalised to 10 taxa. Panel (B) illustrates the $\Delta \Sigma_{\mathrm{cv}}$ of the PETM and ETM2 from Site 1209 compared with the K-Pg using data from Site 1210 (horizontal black line (Bown, 2005)) and Site 1262 (WR - Walvis Ridge, horizontal grey line (Bernaola and Monechi, 2007)). The K-Pg $\Sigma_{\mathrm{cv}}$ value is not plotted against its respective $\delta^{13} \mathrm{C}$ value as this is not a meaningful measure of environmental perturbation for this event.

decreasing sedimentation rate (Fig. 3c). Achieving an above background $\Sigma_{\mathrm{cv}}$ peak (equivalent to a value of around 1.6 $\Sigma_{\mathrm{cv}}$, see Fig. 4a) requires a window size increase to just over $100 \mathrm{~cm}$, which is equivalent to a minimum sedimentation rate reduction of approximately $55 \%$ or a hiatus of just over $50 \mathrm{~cm}$.

In the second sensitivity test, we introduced artificial hiatuses and dissolution levels into one interval that has background variability and one that includes a CIE (Fig. 3d and e). Where the hiatus is introduced into a background interval, we see elevated $\Sigma_{\mathrm{cv}}$ values, but not event-level values, and the longer the hiatus then the greater the apparent increase in $\Sigma_{\mathrm{cv}}$ (Fig. 3d). Where a hiatus was inserted at a CIE, there is little change in the size of $\Sigma_{\mathrm{cv}}$, but some impact on the structure of the record.

For the dissolution test, we removed $75 \%$ of the nannofossils according to their different dissolution susceptibilities (following Gibbs et al., 2010). For example, we removed fewer Discoaster (which are large and robust nannoliths) than we did Campylosphaera (a less robust coccolith). The resulting $\Sigma_{\mathrm{cv}}$ record suggests very little impact on the background assemblages but some amplification of the $\Sigma_{\mathrm{cv}}$ signal across the CIE (Fig. 3e). This is because the background interval assemblages at Site 1209 are dominated by taxa that have very similar dissolution susceptibilities, and so altering their abundances does not result in a major change in their recalculated relative abundances. In contrast, across the CIE intervals, there is a greater contribution by, for example, Zygrhablithus, Discoaster and calcispheres, which increases the range of dissolution susceptibility in the observed dominant taxa. However, the change in $\Sigma_{\mathrm{cv}}$ is relatively small. Therefore, to produce the values of $\Sigma_{\mathrm{cv}}$ associated with the PETM and ETM2 would require substantially larger hiatuses, dissolution or sedimentation rate changes than tested here. Such large sedimentological changes are usually apparent in these deep-sea sediments and so we are confident that this does not account for the larger $\Sigma_{\mathrm{cv}}$ peaks present here. However, variability in the background record of $\Sigma_{\mathrm{cv}}$ may point to potential hiatuses or sedimentation rate changes that are at a resolution higher than the age model, such as the unexplained variability at $\sim 700 \mathrm{kyr}$ above the PETM onset (Fig. 2c).

Finally, by looking at the ranked abundance of taxa from one time interval to the next, we can test whether the fluctuations of dominant taxa are affecting the relative abundance of all the other taxa, for example, the fluctuations of $Z y$ grhablithus. If only Zygrhablithus is changing, then the relative rank of all other taxa should not change. In fact the rank order in the non-Zygrhablithus taxa does change for both the PETM and the ETM2 but does not for the I1. It could be that the Zygrhablithus peak is the only major assemblage shift 
associated with I1, but this does not account for the major assemblage shifts across the PETM and ETM2.

\section{Results and discussion}

\subsection{ODP Site 1209 hyperthermal record}

The majority of the $\Sigma_{\mathrm{cv}}$ values from Site 1209 cluster between 0.4 and $1.6 \Sigma_{\mathrm{cv}}$, supporting the concept of a background range of biotic variability (Figs. 2c, 4a). However, several intervals have values above this range, indicating a magnitude of variability that is exceptional or abovebackground biotic change, and supporting the existence of distinct "events". The highest $\Sigma_{\mathrm{cv}}$ value is associated with the PETM and there is a broadly linear trend of declining $\Sigma_{\mathrm{cv}}$ with decreasing size of CIE for ETM2, I1 and H2 (Figs. 2c and $4 \mathrm{a}$ ), indicating a scaling of biotic response, which is in line with evidence for scaled temperature change and CIEs (Stap et al., 2010). The I2 CIE interval is less clear-cut, as it has an above background $\Sigma_{\mathrm{cv}}$ value if considered within a $150 \mathrm{kyr}$ window, but a background value if using only the CIE duration (Fig. 2c). Similarly, H2 does not show anomalous values of $\Sigma_{\mathrm{cv}}$. This may indicate a biotic sensitivity threshold for calcareous nannoplankton at the Site 1209 location that lies between the CIEs of $\mathrm{H} 2$ and I1, at approximately $0.6 \%$. Alternatively, ETM2 and $\mathrm{H} 2$, and I1 and I2, are relatively closely-spaced $(\sim 100 \mathrm{kyr})$, paired events and nannoplankton communities may not have had time to revert to background compositions. However, nannofloral communities exhibit response and recovery times that are shorter than $100 \mathrm{kyr}$ elsewhere in our records (e.g. the onset of the PETM), and given the short generation times of these plankton, measured in days, this explanation appears unlikely.

Given that carbonate dissolution is associated with each of the CIEs, the scaling between event magnitude and biotic variance might reflect a simple relationship between carbonate erosion and dissolution-skewed abundance patterns. However, the peak dissolution at each event is decoupled from abundance changes (Fig. 6) and the interval of dissolution is shorter than the window across which we have calculated summed correlation of coefficients. Therefore, it is unlikely that $\Sigma_{\mathrm{cv}}$ is an artefact of co-varying dissolution with $\delta^{13} \mathrm{C}$, although, based on the sensitivity tests, there is some potential for the $\Sigma_{\mathrm{cv}}-\delta^{13} \mathrm{C}$ relationship to be amplified.

When applied at higher stratigraphic resolution, the $\Sigma_{\mathrm{cv}}$ metric reveals important details of the timing of the environmental versus biotic perturbation (Fig. 4b). The PETM, ETM2, and I1 events all show elevated $\Sigma_{\mathrm{cv}}$ values in the intervals immediately prior to the CIE onset, and each has recovery intervals in which $\Sigma_{\mathrm{cv}}$ values drop back to background levels before the carbon isotope values, a pattern also observed in temperature and $\mathrm{CaCO}_{3}$ records (Zachos et al., 2003, 2005). This asymmetric structure appears to be a real feature of the events, rather than a data artefact, as

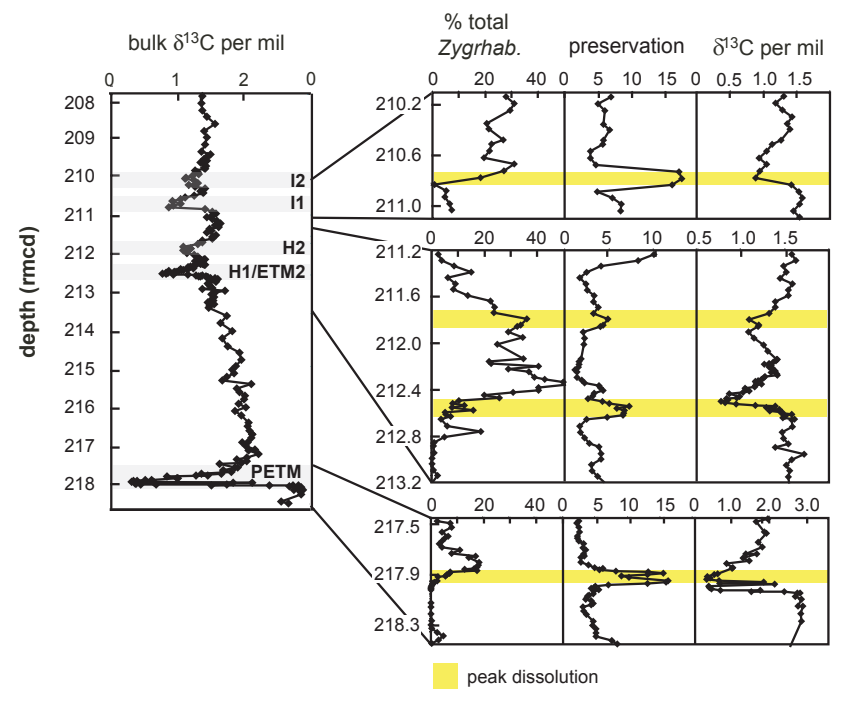

Fig. 6. Relationships between dissolution, the CIEs and the abundance of Zygrhablithus. The nannofossil-based preservation index uses the ratio of indeterminate Toweius to identifiable Toweius with higher values indicating higher levels of dissolution (Gibbs et al., 2006a, 2010). The peak in Zygrhablithus associated with each CIE occurs at the start of the carbon isotope recovery in each case and is consistently above the level of peak dissolution (highlighted in yellow).

it is also seen in the original abundance data (Fig. 1). The shifts in nannoplankton assemblages prior to the respective CIEs are similar to abundance trends seen in PETM planktic foraminiferal and dinoflagellate cyst records from other locations (Thomas et al., 2002; Sluijs et al., 2007b), and our data suggest that similar precursor environmental change also occurred prior to the ETM2 and I1 events.

\subsection{Global levels of variance}

To test the wider significance of our Site 1209 results, we have also analyzed published PETM plankton datasets from a range of shelf, slope and open-ocean localities in the Atlantic, Indian and Southern oceans, and included data for nannoplankton, planktic foraminifera and organic-walled dinoflagellate cysts (Fig. 5a). The background-to-peak CIE $\Sigma_{\mathrm{cv}}$ values $\left(\Delta \Sigma_{\mathrm{cv}}\right)$ for nannoplankton are comparable from these other sites but are slightly higher at high latitude oceanic sites. The planktic foraminifera and dinoflagellate data also indicate comparable ranges of variability (Fig. 5a), but they are consistently higher than the nannofossil records at equivalent sites, perhaps suggesting slightly different relative sensitivities to environmental change in the different plankton groups. For example, dinoflagellate cyst abundance records across the PETM exhibit distinct "acmes" and multiple taxa appear and disappear, resulting in higher variance, as environmental thresholds are crossed across a range of parameters including salinity, trophic state and water depth 
(e.g. Sluijs and Brinkhuis, 2009). In contrast, calcareous nannoplankton records are characterized by abundance shifts in dominant species alongside minor shifts across a range of sub-ordinate taxa, but with few appearances and disappearances. These records demonstrate the integrative power of this analytical approach, which enables comparison of diverse biotic data and provides a means to holistically consider responses to multi-stressor environmental changes, specifically the warming, nutrient and sea-level changes that account for the assemblage variations during the PETM (see Sluijs et al., 2007a). The inclusion of organisms from different functional groups and trophic levels - zooplanktonic planktic foraminifera, oceanic nannoplankton, mixotrophic neritic dinoflagellates - also provides a wider-ranging description of the biotic change, and the results are therefore more broadly representative of the marine ecosystem as a whole.

Finally, in order to place the hyperthermal nannoplankton perturbations in the broadest evolutionary context, we have also analysed data from the K-Pg mass extinction event, $\sim 65 \mathrm{Ma}$, which saw almost complete extermination of the group (Bown, 2005). The K-Pg scenario can therefore be considered an end-member biotic perturbation; i.e. the pre- and post-event assemblages have virtually no taxonomic similarity. The K-Pg $\Sigma_{\mathrm{cv}}$ values from Shatsky Rise Site 1210 (for direct comparison with our hyperthermals dataset, Bown, 2005) and Walvis Ridge in the south Atlantic (Bernaola and Monechi, 2007) are 17 and 14, respectively, with a background-to-peak change of $\sim 10-13$ (Fig. 5b). The Shatsky Rise $\Sigma_{\mathrm{cv}}$ of 17 is close to the theoretical maximum for complete taxonomic turnover at a single event level. The theoretical maximum value can be estimated using different magnitudes of abundance changes across an event level, ranging from low-level to complete turnover in a highly heterogeneous (i.e. uneven) assemblage to low-level to complete turnover in a more homogeneous assemblage. Higher theoretical values are possible only when abundance declines are added prior to the event level turnover.

The spectrum of $\Sigma_{\mathrm{cv}}$ values resulting from analysis of the hyperthermals and K-Pg mass extinction data suggests that the metric is sensitive to biotic response over an extremely wide range of environmental change. This not only allows discrimination between background and event-level intervals but also provides a measure of event-level perturbation magnitude. Therefore, whilst extinction rate data provide a quantitative means of characterizing biotic response to major events such as the K-Pg, the $\Sigma_{\mathrm{cv}}$ metric allows for characterization of biotic response to events, like the hyperthermals, where evolutionary turnover in plankton is relatively modest (Kelly et al., 1998; Gibbs et al., 2006a).

\subsection{Threshold behaviour in plankton records}

These Paleogene plankton data show threshold behaviour and scaled response to the environmental changes associated with carbon cycle perturbations. But is such behaviour inherent in planktonic ecosystems and does this have any relevance for understanding how modern plankton might respond to future ocean change? Specifically, our data show that nannoplankton assemblage perturbations occur with environmental change associated with CIEs of greater than $0.6 \%$, equating to around $2{ }^{\circ} \mathrm{C}$ of global warming, using a proportional relationship between warming and CIE magnitude (Stap et al., 2010). This threshold value, however, may not be directly applicable in the modern ocean. First, rates of carbon cycle change are considerably faster at present, and, second, the modern ocean has different physical baseline conditions (e.g. ocean-atmosphere chemistry and temperature; Zeebe et al., 2009; Goodwin et al., 2009; Ridgwell and Schmidt, 2010), with biological systems today adapted to icehouse climates, rather than the greenhouse climates of the Paleogene. On the one hand the modern ocean system may reach the perturbation threshold more rapidly because of increased rates of change, in addition to the absolute levels of environmental change. By contrast, the greenhouse ocean system may already have been closer to a biologically constrained upper thermal limit and so the threshold would have been reached through relatively smaller environmental changes (see discussion in Huber, 2008). Regardless of the absolute value, this estimate of thermal/carbon-perturbation threshold represents a first-order attempt to place constraints on biological thresholds with the possibility that future biotic response may scale in a similar way to the hyperthermals.

Acknowledgements. This research used samples provided by the Integrated Ocean Drilling Program. We acknowledge research fellowship funding to SJG by the Royal Society and the Natural Environment Research Council (NERC), BHM by a National Science Foundation grant (EAR-0120727 to JCZ), and AS by a Netherlands Organisation of Scientific Research (NWO-Veni grant 863.07.001. We thank Dyke Andreasen for his continued help in operating the UCSC Stable Isotope Lab. Thanks also to Mark Patzkowsky and Tim Bralower for advice and discussions and also to the authors cited for access to their published microfossil data.

Edited by: E. J. Javaux

\section{References}

Abels, H. A., Clyde, W. C., Gingerich, P. D., Hilgen, R. J., Fricke, H. C., Bowen, G. J., and Lourens, L. J.: Terrestrial carbon isotope excursions and biotic change during Palaeogene hyperthermals, Nat. Geosci., 5, 326-329, 2012.

Bernaola, G. and Monechi, S.: Calcareous nannofossil extinction and survivorship across the Cretaceous-Paleogene boundary at Walvis Ridge (ODP Hole 1262C, South Atlantic Ocean), Palaeogeogr., Palaeoclimatol., Palaeoecol., 255, 132-156, 2007.

Bown, P.: Selective calcareous nannoplankton survivorship at the Cretaceous-Tertiary boundary, Geology, 33, 653-656, 2005. 
Bown, P. and Pearson, P.: Calcareous plankton evolution and the Paleocene/Eocene thermal maximum event: New evidence from Tanzania, Mar. Micropal., 71, 60-70, 2009.

Bralower, T. J.: Evidence of surface water oligotrophy during the PETM: Nannofossil assemblage data from Ocean Drilling Program Site 690, Maud Rise, Weddell Sea, Paleoceanography, 17, 0, doi:10.1029/2001PA000662, 2002.

Bralower, T. J., Premoli Silva, I., Malone, M. J., and Shipboard Scientific Party: Chapter 5 Site 1209, Proceedings of the Ocean Drilling Program, Initial Reports, 198, 1-102, doi:10.2973/odp.proc.ir.198.105.2002, 2002.

Chaudhuri, P. and Marron, J. S.: SiZer for Exploration of Structures in Curves, J. Am. Stats. Assoc., 94, 807-823, 1999.

Chaudhuri, P., Marron, J. S., Jiang, J. C., Kim, C. S., Li, R. Z., Rondonotti, V., de Uña Alvarez, J.: SiZer: which features are "really there"?: http://www.unc.edu/ marron/DataAnalyses/ SiZer_Intro.html, last access January 2012.

Cramer, B. S., Wright, J. D., Kent, D. V., and Aubry, M.P.: Orbital forcing of $\delta^{13} \mathrm{C}$ excursions in the late Paleoceneearly Eocene (chrons 24n-25n), Paleoceanography, 18, 1097, doi:10.1029/2003PA000909, 2003.

Gibbs, S. J., Bown, P. R., Sessa, J., Bralower, T. J., and Wilson, P. A.: Nannoplankton extinction and origination rates across the Paleocene-Eocene Thermal Maximum, Science, 314, 17701773, 2006a.

Gibbs, S. J., Bralower, T. J., Bown, P. R., Zachos, J. C., and Bybell, L.: Shelf and open-ocean calcareous phytoplankton assemblages across the Paleocene-Eocene Thermal Maximum: Implications for global productivity gradients, Geology, 34, 233-236, 2006b.

Gibbs, S. J., Stoll, H., Bown, P. R., and Bralower, T. J.: Ocean acidification and surface water carbonate production across the Paleocene-Eocene Thermal Maximum, Earth Planet. Sc. Lett., 295, 583-592, 2010.

Goodwin, P., Williams, R. G., Ridgwell, A., and Follows, M. J.: Climate sensitivity to the carbon cycle modulated by past and future changes in ocean chemistry, Nat. Geosci., 2, 145-150, 2009.

Huber, M.: A hotter greenhouse?, Science, 231, 353-354, 2008.

Kelly, D. C.: Response of Antarctic (ODP Site 690) planktonic foraminifera to the Paleocene-Eocene thermal maximum: Faunal evidence for ocean/climate change, Paleoceanography, 17, 1071, doi:10.1029/2002PA000761, 2002.

Kelly, D. C., Bralower, T. J., and Zachos, J. C.: Evolutionary consequences of the latest Paleocene thermal maximum for tropical planktonic foraminifera, Palaeogeogr., Palaeoclimatol., Palaeoecol., 141, 139-161, 1998.

Lourens, L. J., Sluijs, A., Kroon, D., Zachos, J. C., Thomas, E., Röhl, U., Bowles, J., and Raffi, I.: Astronomical pacing of late Paleocene to early Eocene global warming events, Nature, 435, 1083-1087, 2005.

Lunt, D. J., Ridgwell, A., Sluijs, A., Zachos, J., Hunter, S., and Haywood, A.: A model for orbital pacing of methane hydrate destabilization during the Palaeogene, Nat. Geosci., 4, 775-778, 2011.

McInerney, F. A. and Wing, S. L.: The Paleocene-Eocene Thermal Maximum: Perturbation of carbon cycle, climate, and biosphere with implications for the future, Annu. Rev. Earth Planet. Sci., 39, 489-516, 2011.

Murphy, B. H., Zachos, J. C., McCarren, H. K., Thomas, E., and Roehl, U.: High Resolution Records of the Elmo Event from Shatsky Rise, IODP Sites 1209 \& 1211, Eos Trans. AGU, 87,
Fall Meet. Suppl., PP23C-1777, 2006.

Mutterlose, J., Linnert, C., and Norris, R.: Calcareous nannofossils from the Paleocene-Eocene Thermal Maximum of the equatorial Atlantic (ODP Site 1260B): Evidence for tropical warming, Mar. Micropal., 65, 13-31, 2007.

Petrizzo, M. R.: The onset of the Paleocene-Eocene Thermal Maximum (PETM) at Sites 1209 and 1210 (Shatsky Rise, Pacific Ocean) as recorded by planktonic foraminifera, Mar. Micropal., 63, 187-200, 2007.

Quillévéré, F., Norris, R. D., Kroon, D., and Wilson, P. A.: Transient ocean warming and shifts in carbon reservoirs during the early Danian, Earth Planet. Sc. Lett., 265, 600-615, 2008.

Ridgwell, A. and Schmidt, D. N.: Past constraints on the vulnerability of marine calcifiers to massive carbon dioxide release, Nat. Geosci., 3, 196-200, 2010.

Rohling, E. J. and Pälike, H.: Centennial-scale climate cooling with a sudden cold event around 8,200 years ago, Nature, 434, 975979, 2005.

Sexton, P. F., Norris, R. D., Wilson, P. A., Pälike, H., Westerhold, T., Röhl, U., Bolton, C. T., and Gibbs, S. J.: Eocene global warming events driven by ventilation of oceanic dissolved organic carbon, Nature, 471, 349-352, 2011.

Sluijs, A. and Brinkhuis, H.: A dynamic climate and ecosystem state during the Paleocene-Eocene Thermal Maximum: inferences from dinoflagellate cyst assemblages on the New Jersey Shelf, Biogeosciences, 6, 1755-1781, doi:10.5194/bg-6-17552009, 2009.

Sluijs, A., Bowen, G. J., Brinkhuis, H., Lourens, L. J., and Thomas, E.: The Palaeocene-Eocene Thermal Maximum super greenhouse: biotic and geochemical signatures, age models and mechanisms of global change, in: Deep-Time Perspectives on Climate Change: Marrying the Signal from Computer Models and Biological Proxies, edited by: Williams, M., Haywood, A. M., Gregory, F. J., and Schmidt, D. N., The Micropaleontological Society, Special Publications, The Geological Society, London, 323349, 2007a.

Sluijs, A., Brinkhuis, H., Schouten, S., Bohaty, S. M., John, C. M., Zachos, J. C., Reichart, G.-J., Sinninghe Damsté, J. S., Crouch, E. M., and Dickens, G. R.: Environmental precursors to rapid light carbon injection at the Paleocene/Eocene boundary, Nature, 450, 1218-1221, 2007b.

Sluijs, A., Röhl, U., Schouten, S., Brumsack, H.-J., Sangiorgi, F., Sinninghe Damsté, J. S., and Brinkhuis, H.: Arctic late Paleocene-early Eocene paleoenvironments with special emphasis on the Paleocene-Eocene thermal maximum (Lomonosov Ridge, Integrated Ocean Drilling Program Expedition 302), Paleoceanography, 23, PA1S11, doi:10.1029/2007PA001495, 2008.

Sluijs, A., Schouten, S., Donders, T. H., Schoon, P. L., Röhl, U., Reichart, G.-J., Sangiorgi, F., Kim, J.-H., Sinninghe Damsté, J. S., and Brinkhuis, H.: Warm and Wet Arctic Conditions during Eocene Thermal Maximum 2, Nat. Geosci., 2, 777-780, doi:10.1038/NGEO668, 2009.

Stap, L., Lourens, L. J., Thomas, E., Sluijs, A, Bohaty, S., and Zachos, J. C.: High resolution deep-sea carbon and oxygen isotope records of Eocene Thermal Maximum 2 and H2, Geology, 38, 607-610, 2010.

Thomas, D. J., Zachos, J. C., Bralower, T. J., Thomas, E., and Bohaty, S.: Warming the Fuel for the Fire: Evidence for the thermal dissociation of methane hydrate during the Paleocene-Eocene 
thermal maximum, Geology, 30, 1067-1070, 2002.

Wagner, D. H.: SiZer download page: http://www.wagner.com/ SiZer/SiZerDownload.html, last access January 2012.

Westerhold, T. and Röhl, U.: Data report: revised composite depth records for Shatsky Rise Sites 1209, 1210, and 1211, Proc. Oc. Drill. Prog., Sci. Res., 198, 1-26, doi:10.2973/odp.proc.sr.198.122.2006, 2006.

Zachos, J. C., Wara, M. W., Bohaty, S., Delaney, M. L., Petrizzo, M. R., Brill, A., Bralower, T. J., and Premoli-Silva, I.: A transient rise in tropical sea surface temperature during the PaleoceneEocene Thermal Maximum, Science, 302, 1551-1554, 2003.
Zachos, J. C., Röhl, U., Schellenberg, S. A., Appy Sluijs, A., Hodell, D. A., Kelly, D. C., Thomas, E., Nicolo, M., Raffi, I., Lourens, L. J., McCarren, H., and Kroon, D.: Rapid Acidification of the Ocean During the Paleocene-Eocene Thermal Maximum, Science, 308, 1611-1615, 2005.

Zachos, J. C., McCarren, H., Murphy, B., Röhl, U., and Westerhold, T.: Tempo and scale of late Paleocene and early Eocene carbon isotope cycles: Implications for the origin of hyperthermals, Earth Planet. Sci. Lett., 299, 242-249, 2010.

Zeebe, R. E., Zachos, J. C., and Dickens, G. R.: Carbon dioxide forcing alone insufficient to explain Palaeocene-Eocene Thermal Maximum warming, Nat. Geosci., 2, 576-580, 2009. 